\title{
Design and Control of the Phase Shift Full Bridge Converter for the On-board Battery Charger of Electric Forklifts
}

\author{
Tae-Hoon Kim*, Seung-Jun Lee*, and Woojin Choi ${ }^{\dagger}$ \\ $\dagger^{*}$ Dept. of Electrical Engineering, Soongsil University, Seoul, Korea
}

\begin{abstract}
This paper describes the design and control of a phase shift full bridge converter with a current doubler, which can be used for the on-board charger for the lead-acid battery of electric forklifts. Unlike the common resistance load, the battery has a large capacitance element and it absorbs the entire converter output ripple current, thereby shortening the battery life and degrading the system efficiency. In this paper a phase shift full bridge converter with a current doubler has been adopted to decrease the output ripple current and the transformer rating of the charger. The charge controller is designed by using the small signal model of the converter, taking into consideration the internal impedance of the battery. The stability and performance of the battery charger is then verified by constant current (CC) and constant voltage (CV) charge experiments using a lead-acid battery bank for an electric forklift.
\end{abstract}

Key Words: Electric Forklift, Lead-Acid Battery, On-Board Charger, Phase-Shift Full Bridge Converter

\section{INTRODUCTION}

Forklifts are classified into LPG engine forklifts, diesel engine forklifts and electric forklifts depending on their power source. Diesel engine forklifts have been favored at industrial sites because they have excellent torque and good durability. Recently, however, electric forklifts are becoming more widely used because they do not emit exhaust gas and produce little noise and pollution. The use of electric forklifts suitable for indoor environments is increasing every year in various businesses such as large distribution centers and food storing warehouses. The batteries used as the power source for electric forklifts should be able to discharge large amounts of electric current within a short period of time. Therefore, lead-acid batteries are mainly used for electric forklifts due to their large discharge current rate. Their heavy weight, generally considered as a disadvantage, may be turned into an advantage if the fact that they have to load and unload heavy objects is taken into consideration. This is due to the fact that heavy batteries help to maintain the center of gravity.

The power electronic topologies for high power battery chargers can be largely classified into two categories: single stage types and two stage types [1]-[3]. Single stage battery chargers generally share the semiconductor switch and the controller. Since they combine the power factor correction

\footnotetext{
Manuscript received Jul. 30, 2011; revised Dec. 7, 2011

Recommended for publication by Associate Editor Honnyong Cha.

† Corresponding Author: cwj777@ssu.ac.kr

Tel: +82-2-860-0652, Fax: +82-2-817-7961, Soongsil University

${ }^{*}$ Dept. of Electrical and Engineering, Soongsil University, Korea
}

stage and the DC-DC conversion stage into one, they can be more efficient than the two stage types. However, single stage type battery chargers have a low frequency ripple in the output, where the frequency is double the utility frequency. As a result, the switch and transformer ratings become larger [1]. The two stage types generally use a boost type converter to improve the power factor at the first stage and a DCDC converter for the control of the voltage and current at the second stage. Two stage power converters can make the input current into a high quality sinusoid form, which is in phase with the input voltage. They use their own controllers to control the input current and the output voltage at the same time. The two stage types have a higher power factor and a lower harmonic distortion. They have an advantage that there is almost no low frequency ripple in the output. However, they require more power semiconductor switches than the single stage type. Since they use an additional controller for power factor correction, the two stage type is generally used for large capacity systems [2], [3].

In this paper, the design and control algorithm for the phase shift full bridge converter of the two stage type battery charger for lead-acid batteries are discussed. The current ratings of the transformer and the output current ripple are reduced by adopting a current doubler type rectifying circuit at the secondary side of the DC-DC converter. A small signal model of the converter, taking into consideration the internal impedance of the battery, is also presented. The procedure for designing the charge controller is also detailed. A $3 \mathrm{~kW}$ battery charger is implemented to demonstrate the stability 


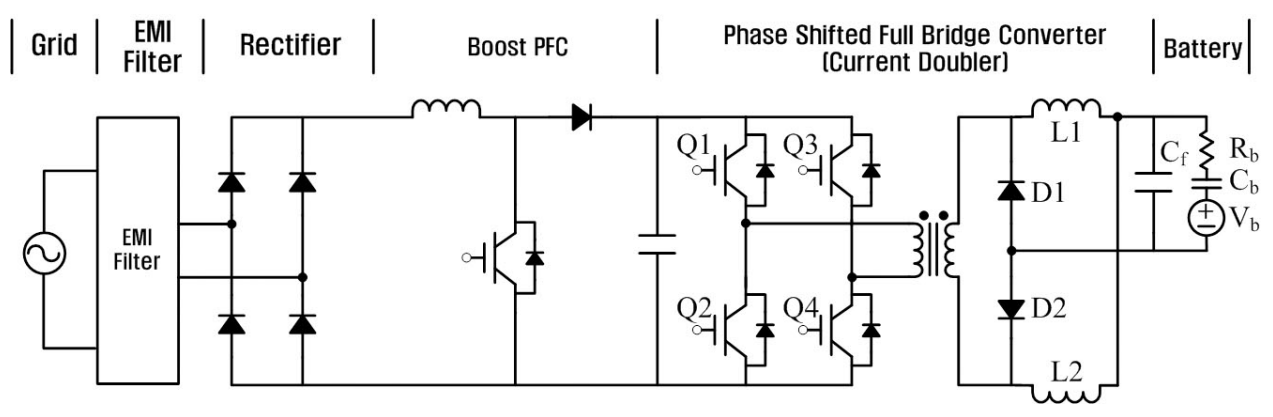

Fig. 1. Circuit diagram of the two stage battery charger for the electric forklift.

and performance of the system. The validity of the concept is then verified through the constant current (CC) mode and the constant voltage $(\mathrm{CV})$ mode charge of an actual lead-acid battery bank for an electric forklift.

\section{Operation of a Full Bridge Phase Shift DC-DC Converter With a Current Doubler}

Fig. 1 shows an overall circuit diagram of a two stage type battery charger system for an electric forklift. The system consists of an EMI filter, a bridge rectifier, a PFC circuit and a DC-DC converter. Regarding the DC-DC converter, a current doubler type phase shift full bridge converter with two inductors is used.

The phase shift full bridge converter can achieve soft switching by phase-shifting the gate signals between the leading-leg and the lagging-leg switches without additional circuits. Therefore, the switching loss can be decreased and the efficiency can be enhanced. Thus the circuit is suitable for middle to large capacity battery chargers since the volume and weight of the converter can be reduced significantly by high frequency switching [4]. The current doubler circuit is advantageous in that it can decrease the secondary current rating of the transformer and the effective frequency of the output capacitor is double the switching frequency [5].

Therefore, it can be useful for high-current low-voltage application such as an electric forklift battery charger. Fig. 2 shows the voltage and current waveforms of the converter operating in the steady-state. The converter operation can be divided into three modes: 'power delivery mode', 'freewheeling mode' and 'commutation mode' [6]. The principles of the converter operation are as follows.

1) Mode $1\left(t_{0}-t_{1}\right.$, Fig. 3(a)): The power is delivered from the primary to the secondary in this mode. Q1 and Q4 are conducted and the input voltage is applied to the primary side of the transformer. The diode D1 in the secondary side becomes reverse biased and only D2 is conducted. Therefore, the inductor current $I_{L 1}$ increases linearly while the inductor current $\mathrm{I}_{L 2}$ decreases linearly. They can be expressed as (1) and (2), respectively.

$$
\begin{gathered}
i_{L 1}(t)=i_{L 1}\left(t_{0}\right)+\frac{\left(N_{s} / N_{p}\right) V_{i n}-V_{o}}{L_{1}}\left(t-t_{0}\right) \\
i_{L 2}(t)=i_{L 2}\left(t_{0}\right)-\frac{V_{o}}{L_{2}}\left(t-t_{0}\right) .
\end{gathered}
$$

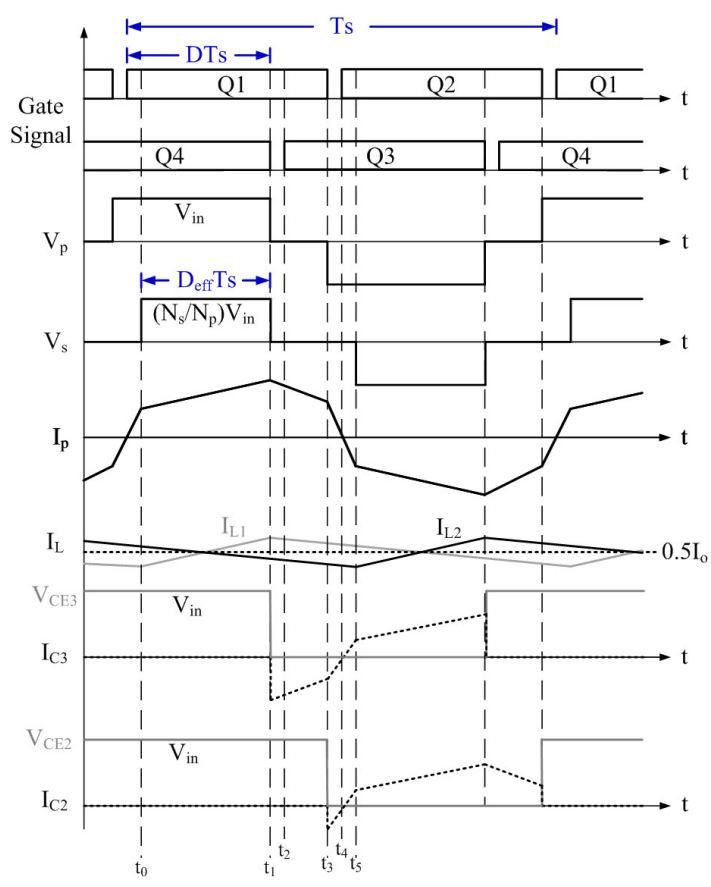

Fig. 2. Voltage and current waveforms of the converter in the steady-state.

2) Mode $2\left(t_{1}-t_{2}\right.$, Fig. 3(b, c)): As shown in Fig. 3(b), when the switch Q4 is off, the energy stored in the output filter inductor L1 discharges the parasitic capacitance of the switch Q3 and simultaneously charges the parasitic capacitance of the switch Q4. ZVS (Zero Voltage Switching) can be achieved when the condition in the (3) is satisfied, where $\mathrm{C}_{\text {oss }}$ is the parasitic capacitance of the switch.

$$
E=\frac{1}{2} L_{1}\left(i_{L 1}\left(t_{1}\right)\right)^{2} \geq \frac{4}{3} C_{o s s} V_{i n}^{2} .
$$

Since the value of the inductor L1 is very large, this condition can be satisfied easily. Thus, the switches of leading leg (Q3, Q4) can achieve ZVS in a wide load range.

When all of the output diodes are conducted and have participated in the freewheeling operation, the voltage of the transformer becomes zero. As can be seen in Fig. 3(c), the antiparallel diodes of Q1 and Q3 are conducted in the primary side and the ZVS switching of Q3 becomes possible. The currents for each of the inductors at this time can be expressed as follows:

$$
i_{L 1}(t)=i_{L 1}\left(t_{1}\right)+\frac{V_{o}}{L_{1}}\left(t-t_{1}\right)
$$




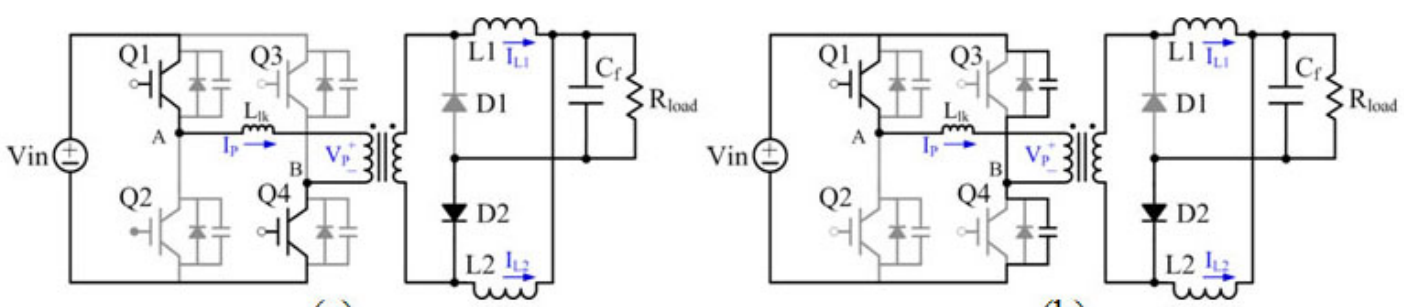

(a)

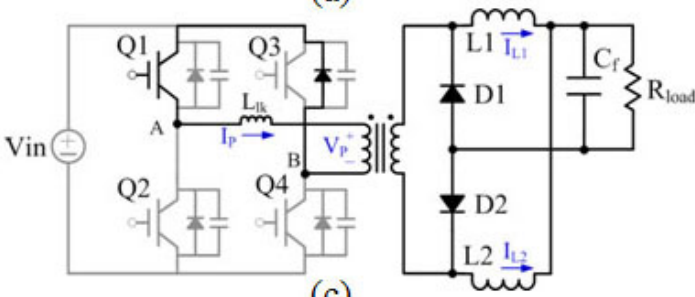

(b)

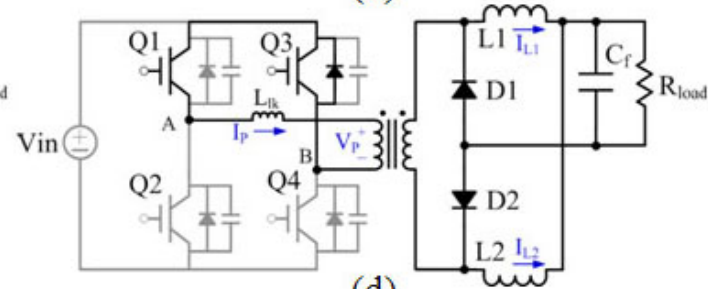

(d)

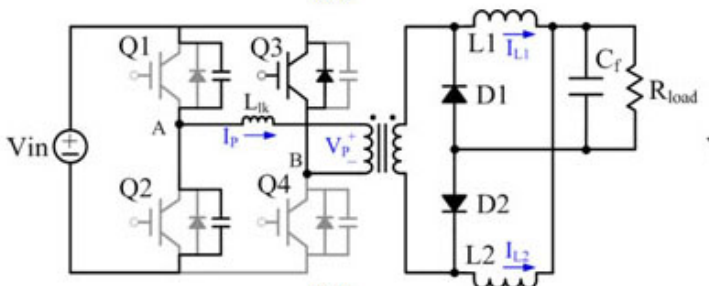

(e)

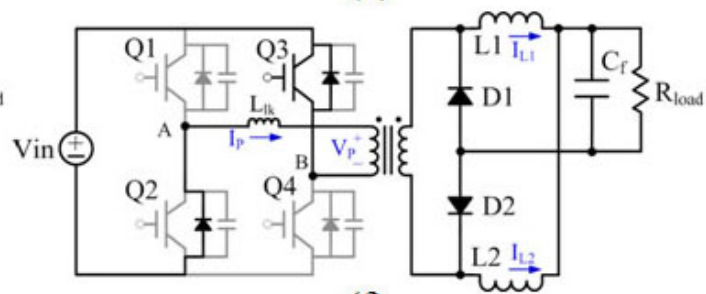

(f)

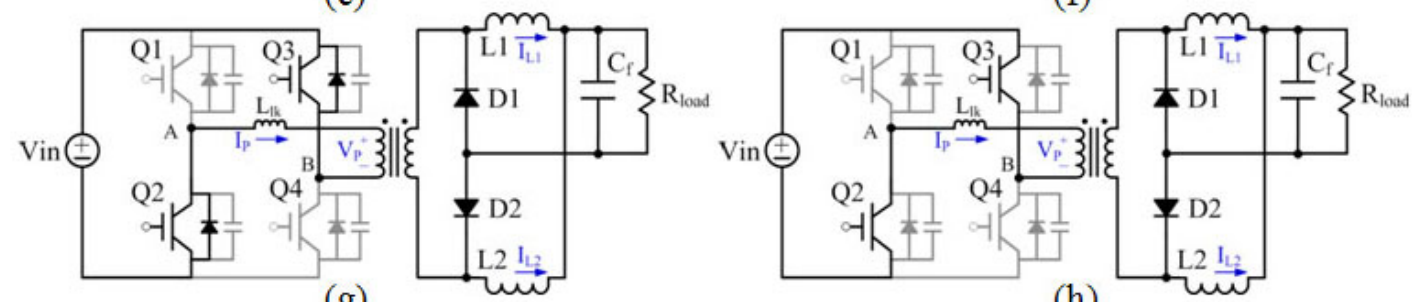

(g)

(h)

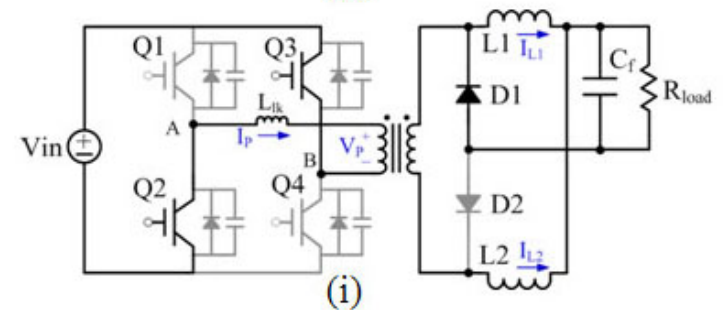

Fig. 3. Operation modes of the converter.

$$
i_{L 2}(t)=i_{L 2}\left(t_{1}\right)-\frac{V_{o}}{L_{2}}\left(t-t_{1}\right) .
$$

3) Mode $3\left(t_{2}-t_{3}\right.$, Fig. 3(d)): In this mode, the switch Q3 turns-on and ZVS can be achieved. The secondary side maintains the freewheeling operation. Each of the inductor currents can be expressed by (4) and (5).

4) Mode $4\left(t_{3}-t_{4}\right.$, Fig. 3(e, f)): As can be seen in Fig. 3(e), the switch Q1 is turned-off at $t_{3}$. The energy stored in the transformer leakage inductance $\mathrm{L}_{l k}$ will charge and discharge the parasitic capacitors of the switches Q1 and Q2, respectively. The ZVS condition can be expressed by (6) in this mode.

$$
E=\frac{1}{2} L_{l k}\left(i_{P}\left(t_{3}\right)\right)^{2} \geq \frac{4}{3} C_{\text {oss }} V_{\text {in }}^{2} .
$$

Then, as shown in Fig. 3(f), the anti-parallel diodes of the switches Q2 and Q3 become conducted and the voltage $-\mathrm{V}_{\text {in }}$ is applied to the primary side of the transformer. The switch
Q2 is ready for ZVS in this mode. As can be seen in $t_{3}-t_{4}$ of Fig. 2, the current in this section has a steep slope. Since the direction of the current is reversed in the next mode, it is not easy to achieve ZVS of the lagging leg (Q1, Q2).

5) Mode $5\left(t_{4}-t_{5}\right.$, Fig. 3(g, h)): As can be seen in Fig. 3(g), the switch Q3 turns on as soon as this mode begins and ZVS is achieved. In this mode the current flowing through the antiparallel diodes of the switches Q2 and Q3 changes its direction and then flows through each of the switches as can be seen in Fig. 3(h). At this moment, however, since the currents in the rectifying diodes in the secondary side are not completely commutated, all of the rectifying diodes are forward biased. The currents in the output filter inductors continue to decrease. In other words, even the switches Q2 and Q3 are conducted. Power delivery does not happen in this period and the actual duty ratio decreases because of $\mathrm{L}_{l k}$. Therefore, the effective 


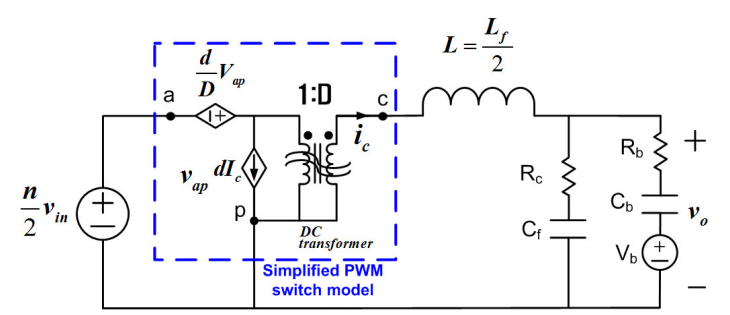

Fig. 4. Small signal equivalent circuit model of the phase shift full bridge converter with a simplified PWM switch model.

duty $\mathrm{D}_{\text {eff }}$ of the converter can be expressed as (7). The duty loss $\Delta \mathrm{D}$ is as (8) [7].

$$
\begin{gathered}
D_{\text {eff }}=D-\Delta D \\
\Delta D=\frac{i_{P}\left(t_{0}\right)+i_{P}\left(t_{3}\right)}{\left(V_{i n} / L_{l k}\right) T_{s}} .
\end{gathered}
$$

Then the switching sequence will repeat from mode 1 to mode 5 in the reverse direction during the other half of the cycle. In the steady-state, the output voltage of the converter can be expressed as follows:

$$
V_{o}=\frac{\left(N_{S} / N_{P}\right) D_{e f f} V_{i n}}{2}
$$

\section{Converter Modeling And Controller Design}

A. Converter Modeling Considering the Internal Impedance of the Battery

The state space averaging method can be used for the modeling of the phase shift full bridge converter. However, in its application, the equation becomes very complicated because first the equation for each operation mode of the circuit should be established and then the average needs to be taken from them [8]. Therefore, it would be better to derive a small signal equivalent circuit model using the simplified PWM switch model [9], [10].

Since the output current of a full bridge converter with a current doubler is the sum of two filter inductor currents, an equivalent circuit can be expressed as two buck converters connected in parallel. In addition, the transfer function for the average current-mode control of the buck converter can be used as the small signal transfer function of the converter because the output filter inductor currents are not controlled individually. Even though there may be some differences in the average current of each inductor, its average value can be assumed to be the same since the transformer flux balancing is maintained by the input side DC blocking capacitor [9]. If the simplified PWM switch model is applied and the transformer is assumed to be ideal, the small signal model of the converter can be expressed as Fig. 4.

Due to the fact that two output inductors share a single output filter capacitor in the current doubler circuit, the value of the inductor in the equivalent circuit model becomes half of its original value. In order to derive the transfer function of the above circuit, it is necessary to include the internal impedance of the lead acid battery. There are various equivalent impedance models for lead-acid batteries [11], [12]. However, in this paper, it has been modeled simply with a series circuit composed of a resistance $\left(\mathrm{R}_{b}\right)$, a capacitor $\left(\mathrm{C}_{b}\right)$ and a voltage source $\left(\mathrm{V}_{b}\right)$, as can be seen in Fig. 4. The equivalent capacitance $\mathrm{C}_{b}$ can be obtained from the charge/voltage relationship of the capacitor $(\mathrm{Q}=\mathrm{CV})$. The equivalent series resistance $\mathrm{R}_{b}$ can be obtained by using the time-constant $\left(\tau_{b}\right)$ of the battery, calculated from the current profile during the constant voltage mode, and the previously calculated capacitance $\left(\mathrm{C}_{b}\right)$ as follows: $\mathrm{R}_{b}=\tau_{b} / \mathrm{C}_{b}$.

In order to simplify the transfer functions of the converter, the equivalent impedance $\mathrm{Z}_{e q}$, which represents the total impedance of the output filter capacitor and the battery, is defined as follows:

$$
\begin{aligned}
Z_{e q} & =\left(R_{b}+\frac{1}{s C_{b}}\right) \|\left(R_{c}+\frac{1}{s C_{f}}\right) \\
& =\frac{s^{2}\left(R_{b} C_{b} R_{c} C_{f}\right)+s\left(R_{b} C_{b}+R_{c} C_{f}\right)+1}{s^{2}\left(C_{b} R_{c} C_{f}+C_{f} R_{b} C_{b}\right)+s\left(C_{b}+C_{f}\right)} .
\end{aligned}
$$

The transfer function and input impedance of the output filter can be defined as (11) and (12).

$$
\begin{gathered}
H_{o}(s)=Z_{e q} /\left(s L+Z_{e q}\right) \\
Z_{f}(s)=1 /\left(s L+Z_{e q}\right) .
\end{gathered}
$$

Therefore, the control-to-output filter inductor current transfer function $\mathrm{G}_{i d}$ can be expressed as (13) and the control-tooutput voltage transfer function can be expressed as (14).

$$
\begin{aligned}
G_{i d}(s) & =\hat{i}_{L}(s) / \hat{d}(s)=n V_{i n} / 2 Z_{f} \\
G_{v d}(s) & =\hat{v}_{o}(s) / \hat{d}(s)=H_{o} n V_{i n} / 2 .
\end{aligned}
$$

\section{B. Design of the Charge Controller}

Fig. 5 is a block diagram of the battery charge control algorithm using a double control loop. It consists of an external control loop, regulating the converter output voltage (CV mode), and an internal control loop, regulating the inductor current (CC mode). In the control, the output voltage $\left(\mathrm{v}_{o}\right)$ is detected and compared with the reference voltage $\left(\mathrm{v}_{o}{ }^{*}\right)$. Then an error signal is generated and amplified to generate a current reference $\left(i_{L} *\right)$. Since the charge control begins with the constant current (CC) mode, the current reference should be limited at the appropriate charge current of the battery $(0.12 \mathrm{C}$ in this case). The current reference $\left(i_{L} *\right)$ is then compared with the detected inductor current $\left(i_{L}\right)$. Then an error signal is generated, which is transmitted to the current controller. The output of the current controller is then compared with a triangular wave to generate the PWM signal for the switches. At this time, the loop gain of the internal current loop and the external voltage loop can be expressed as follows [13].

$$
\begin{gathered}
T_{i}(s)=G_{i c} \times 1 / V_{m} \times G_{i d} \times H_{i} \\
T_{v}(s)=\frac{G_{v c} \times G_{i c} \times 1 / V_{m} \times G_{v d} \times H_{v}}{1+T_{i}}
\end{gathered}
$$

where, $\mathrm{G}_{i c}$ is the current controller gain, $H_{i}$ is the current feedback gain, $1 / \mathrm{V}_{m}$ is the comparator gain, $\mathrm{G}_{v c}$ is the voltage controller and $\mathrm{H}_{v}$ is the voltage feedback gain.

Fig. 6 shows the design process of the current and voltage controller using bode plots. As can be seen in Fig. 6(a), the 


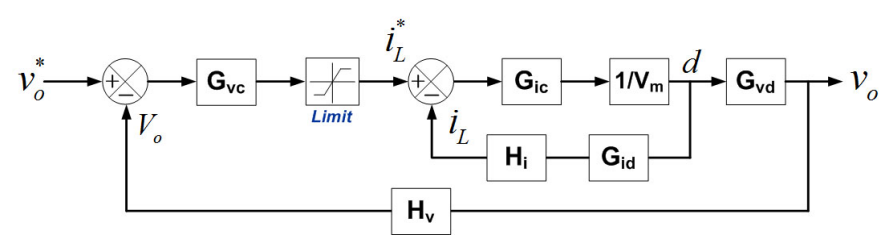

Fig. 5. Block diagram of the battery charge control algorithm using double control loop.

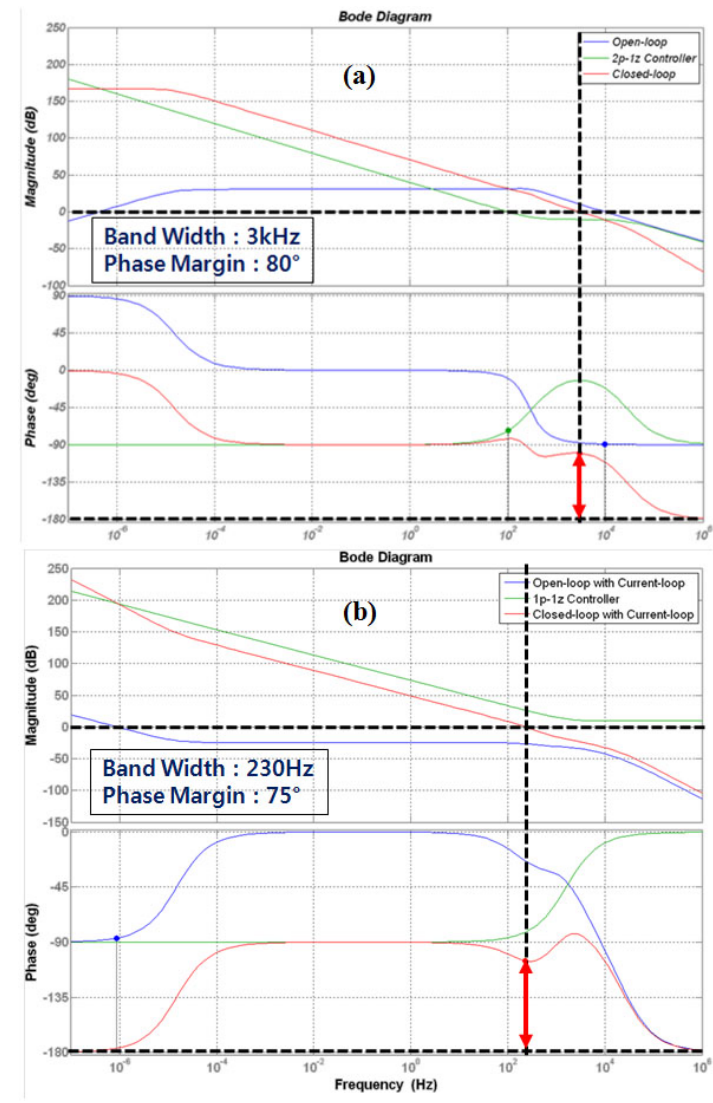

Fig. 6. Design of the battery charge controller using bode plot (a) current control loop (b) voltage control loop.

crossover frequency of the current controller is selected as $3 \mathrm{kHz}$. The control transfer function (the blue line) at the crossover frequency shows that the slope of the gain plot is $-20 \mathrm{~dB} / \mathrm{dec}$ and that the phase is -90 degree. It can be seen that the phase margin is enough as it is. However, the gain in the low frequency region is not high enough because of the huge capacitance element of the battery. Therefore, a two-pole, onezero controller is selected to increase the low frequency gain by locating one pole at the origin. The zero is located before the system double pole and the other pole is located before half of the switching frequency so that the system can become insensitive to high frequency noise. The design also secures a sufficient phase margin of 80 degree at the crossover frequency for the stability of the system [14]. Fig. 6 (b) is a bode plot of the voltage loop controller. The crossover frequency of the voltage controller is selected as $230 \mathrm{~Hz}$, which is somewhat low. Such a low crossover frequency may result in a slow dynamic characteristic of the converter. However, it may not be critical for the charge application because the battery voltage does not vary rapidly during charging. The phase plot of the controller transfer function (the blue line) at

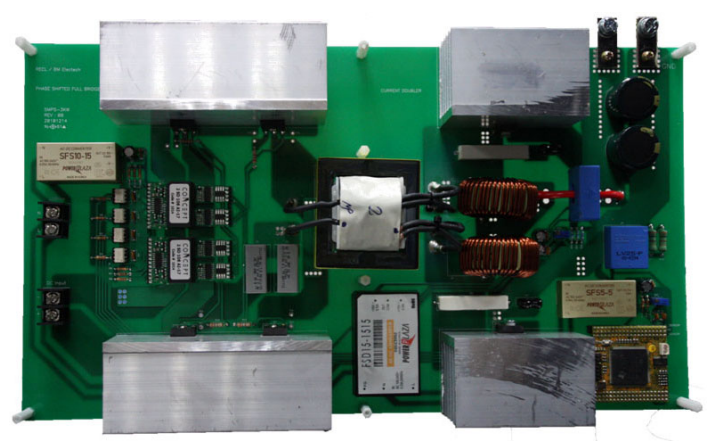

(a)

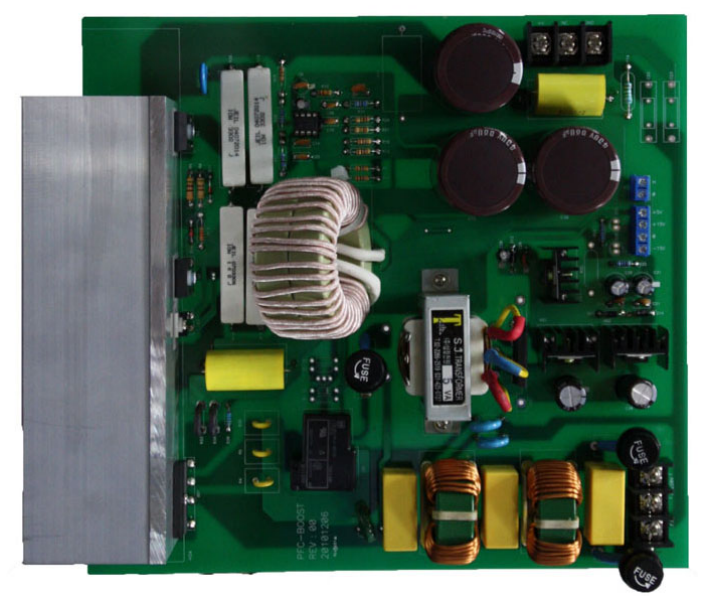

(b)

Fig. 7. Developed $3 \mathrm{~kW}$ battery charger for the electric forklift. (a) DC-DC converter. (b) PFC converter.

TABLE I

SPECIFICATION OF THE LEAD-ACID BATTERY BANK

\begin{tabular}{|l|l|l|}
\hline & Type & Lead-Acid \\
Capacity & $365 \mathrm{AH}$ \\
Weight & $615 \mathrm{~kg}$ \\
Rated voltage & $48.0 \mathrm{~V}(24$ cells $)$ \\
& Maximum voltage & $56.4 \mathrm{~V}$ \\
& Minimum voltage & $42.0 \mathrm{~V}$ \\
& Specific gravity & $1.280 / 25^{\circ} \mathrm{C}$ \\
& Charge method & $\mathrm{CC} / \mathrm{CV}$ \\
\hline
\end{tabular}

the crossover frequency suggests that it has a sufficient phase margin. However, the gain plot shows a low value and a flat characteristic. Thus, a PI controller is used for the gain curve to have $-20 \mathrm{~dB} / \mathrm{dec}$ slope at the crossover frequency and a higher gain in the low frequency region.

TABLE II

Specification of The Developed Charge Converter

\begin{tabular}{|l|l|l|}
\hline Input voltage & $\mathrm{V}_{i n}$ & $400 \mathrm{~V}$ \\
Output voltage & $\mathrm{V}_{o}$ & $56.4 \mathrm{~V}$ \\
Output power & $\mathrm{P}_{o}$ & $3 \mathrm{~kW}$ \\
Transformer turns ratio & $\mathrm{N}_{P}: \mathrm{N}_{S}$ & $15: 6$ \\
Magnetizing inductance & $\mathrm{L}_{m}$ & $1.38 \mathrm{mH}$ \\
Leakage inductance & $\mathrm{L}_{l k}$ & $7.5 \mu \mathrm{H}$ \\
Switching frequency & $\mathrm{f}_{s}$ & $60 \mathrm{kHz}$ \\
Output filter inductor & $\mathrm{C}_{f}$ & $3000 \mu \mathrm{F}$ \\
Output filter capacitor & $\mathrm{L}_{1,2}$ & $130 \mu \mathrm{H}$ \\
IGBTs & $\mathrm{Q}_{1,2,3,4}$ & $\mathrm{STGW} 35 \mathrm{HF} 60 \mathrm{WD}$ \\
Diodes & $\mathrm{D}_{1,2}$ & APT60S20B \\
Equivalent capacitance of the battery & $\mathrm{C}_{b}$ & $91250 \mathrm{~F}$ \\
Equivalent seriesresistance of the battery & $\mathrm{R}_{b}$ & $118 \mathrm{~m} \Omega$ \\
\hline
\end{tabular}




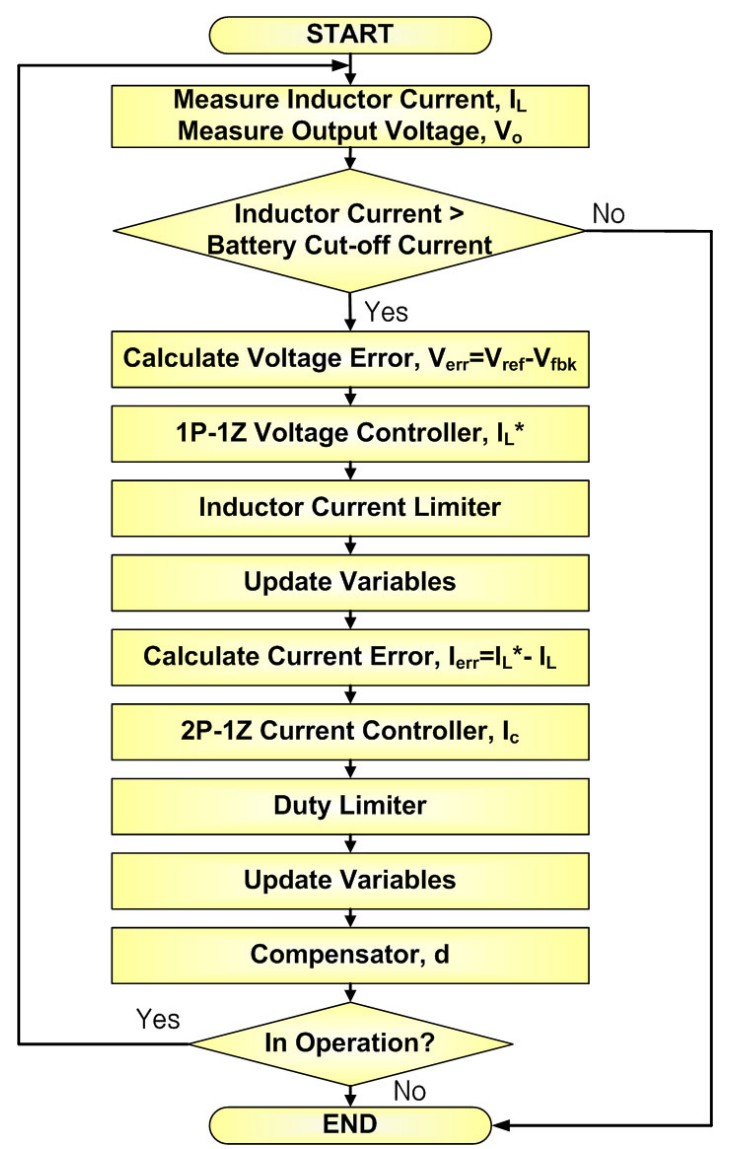

Fig. 8. Flow chart of the control algorithm implemented in the digital signal processor.

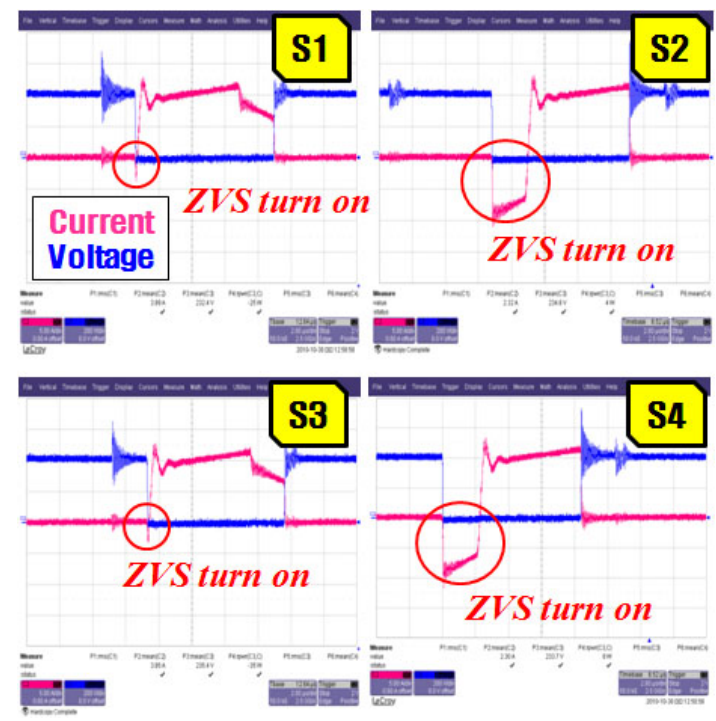

Fig. 9. Voltage and current waveforms of the IGBT switches.

\section{Measurement Results and Discussions}

In order to verify the validity of the developed battery charger and control algorithm, a circuit is implemented, as can be seen in Fig. 7, and an actual lead-acid battery bank, as shown in Table I, is charged. Table I also shows the specifications for the lead-acid battery bank used in the experiments. Table II shows the specifications for the developed charge converter.

A commercial continuous current-mode controller, IC 'NCP

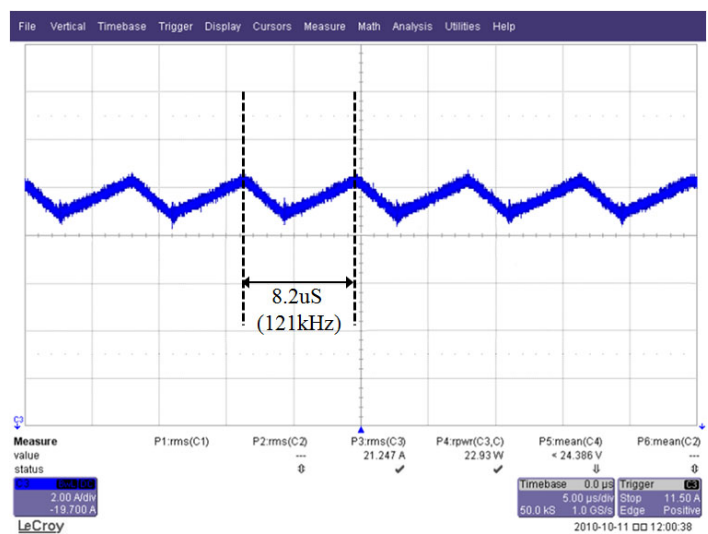

Fig. 10. Current waveform at the common connection of the two output filter inductors.

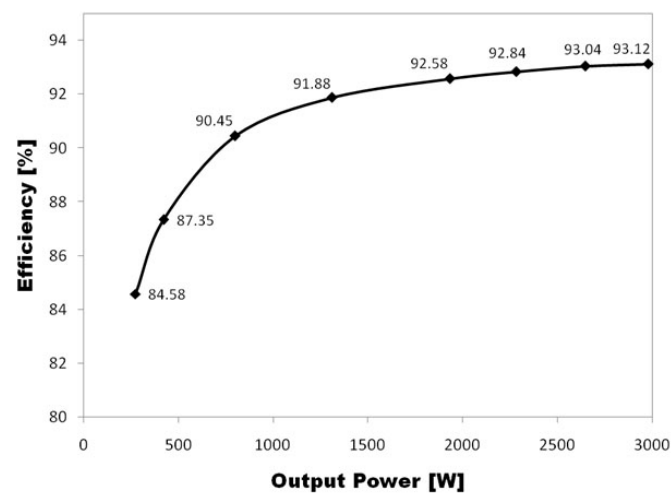

Fig. 11. The measured efficiency plot of the charge converter.

1653A' from ON Semiconductor, is used for the PFC control. In order to create the $\mathrm{CC} / \mathrm{CV}$ mode control algorithm mentioned in the previous section, a DSP (Digital Signal Processor), 'TMS320F28335' from TI, is used for the full digital control of the converter. Fig. 8 is a flow chart of the control algorithm implemented in the DSP. In order to detect the current of the filter inductor, a current transducer, 'LA100$\mathrm{P}$ ' from LEM, is used. A voltage transducer, 'LV25-P' from LEM, is used to detect the output voltage. For the digital implementation of the designed analog controller, a bilinear transformation is used. The resulting equation is as follows:

$$
\begin{gathered}
G_{i c}(z)=\frac{0.1837+0.0062 z^{-1}-0.1775 z^{-2}}{1.0000-0.8177 z^{-1}-0.1823 z^{-2}} \\
G_{v c}(z)=\frac{3.2500-2.7500 z^{-1}}{1.0000-1.0000 z^{-1}} .
\end{gathered}
$$

Fig. 9 shows the voltage and current waveforms of the IGBT switches, where each switch achieves ZVS turn-on. It can be seen that the switches (Q3, Q4) of leading leg achieves ZVS by using the energy stored in the output filter inductor. The switches of the lagging leg (Q1, Q2) achieve ZVS using the energy stored in the leakage inductance. Therefore, the current changes its direction rapidly and as a result, the ZVS turn-on area is narrow.

Fig. 10 shows the current waveform at the common connection of the two output filter inductors. As can be seen, the frequency of the output current is double the switching frequency $(60 \mathrm{kHz})$. The efficiency of the charge converter 


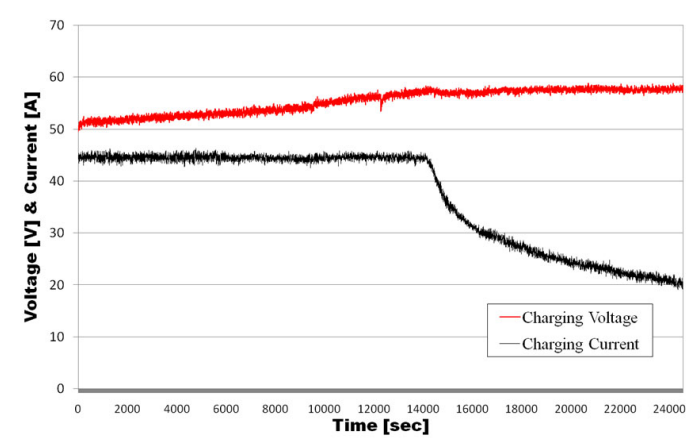

Fig. 12. Voltage and current waveforms of the actual lead-acid battery bank for the electric forklift during the $\mathrm{CC} / \mathrm{CV}$ charge.

is measured by a digital power meter, 'WT1600' from Yokogawa. As can be seen in Fig. 11, the efficiency is $84.58 \%$ under a light load and $93.12 \%$ under the rated load. Fig. 12 shows the voltage and current plots of the lead-acid battery for an electric forklift during the $\mathrm{CC} / \mathrm{CV}$ charge using the developed converter in this paper. As can be seen, the battery charge current is regulated at a reference value of $45 \mathrm{~A}(0.12 \mathrm{C})$ during the $\mathrm{CC}$ mode charge period. The voltage of the battery bank gradually increases until it reaches to the upper limit of the charge voltage. Then the battery charger automatically shifts to the CV mode by the control algorithm. In the CV mode, the battery voltage is kept constant at $57.4 \mathrm{~V}$ and the charge current decreases exponentially.

\section{CONCLUSIONS}

This paper described the design and control of a phase shift full bridge converter with a current doubler, which can be used to charge the lead acid battery bank of an electric forklift. A $3 \mathrm{~kW}$ converter was designed and implemented to verify the validity of the developed control algorithm and system. It has been verified that the $\mathrm{CC} / \mathrm{CV}$ mode charge algorithm can be simply created by a double control loop for the inductor current and the converter output voltage. It can be concluded that the developed converter may contribute to a higher system efficiency and a longer battery life due to its lower ripple current characteristics.

\section{ACKNOWLEDGMENT}

This work (research) was financially supported by the Ministry of Knowledge Economy (MKE) and Korea Institute for Advancement in Technology (KIAT) through the Workforce Development Program in Strategic Technology.

This work was supported by the 20104010100610 of the Korea Institute of Energy Technology Evaluation and Planning (KETEP) grant funded by the Ministry of Knowledge Economy, Republic of Korea.

This work was supported by MKE/KEIT Human Resource Training Project for Convergence Renewable Energy Sources.

\section{REFERENCES}

[1] J.-G. Cho, C.-Y. Jeong, H.-S. Lee, and G.-H. Rim, "Novel zero-voltagetransition current-fed full-bridge pwm converter for single-stage power factor correction," IEEE Trans. Power Electron., Vol. 13, No. 6, pp. 1005-1012, Nov. 1998.
[2] J. Zhang, M. M. Jovanovic, and F. C. Lee, "Comparison between CCM single-stage and two-stage boost PFC converters," in Proc. APEC, Vol. 1, pp. 335-341, 1999.

[3] B. Sharifipour, J. S. Huang, P. Liao, L. Huber, and M. M. Jovanovic, "Manufacturing and cost analysis of power-factor-correction circuits," in Proc. APEC, Vol. 1, pp. 490-494, 1998.

[4] E. Pepa, "Adaptive control of a step-up full-bridge dc-dc converter for variable low input voltage applications," Masters Thesis, Virginia Polytechnic Institute and State University, 2004.

[5] N. H. Kutkut, D. M. Divan, and R. W. Gascoigne, "An improved fullbridge zero-voltage switching PWM converter using a two-inductor rectifier," IEEE Trans. Ind. Appl., Vol. 31, No. 1, pp. 119-126, Jan./Feb. 1995.

[6] N. H. Kutkut, "A full bridge soft switched telecom power supply with a current doubler rectifier," in Proc. INTELEC, pp. 344-351, 1997.

[7] B.-Y. Chen, and Y.-S. Lai, "Switching control technique of phase-shiftcontrolled full-bridge converter to improve efficiency under light-load and standby conditions without additional auxiliary components," IEEE Trans. Power Electron., Vol. 25, No. 4, pp. 1001-1012, Apr. 2010.

[8] V. Vlatkovic, J. A. Sabate, R. B. Ridley, F. C. Lee, and B. H. Cho, "Small-signal analysis of the phase-shifted PWM converter," IEEE Trans. Power Electron., Vol. 7, No. 1, pp. 128-135, Jan. 1992.

[9] N. H. Kutkut and G. Luckjiff, "Current mode control of a full bridge DC-to-DC converter with a two inductor rectifier," in Proc. PESC, Vol. 1, pp. 203-209, 1997.

[10] L. Cao, "Small signal modeling for phase-shifted pwm converters with a current doubler rectifier," in Proc. PESC, pp. 423-429, 2007.

[11] A. Jossen, "Fundamentals of battery dynamics," J. Power Sources, Vol. 154, No. 2, pp. 530-538, Mar. 2006.

[12] B. Hariprakasha, S. K. Marthaa, A. Jaikumara, and A. K. Shukla, "Online monitoring of lead-acid batteries by galvanostatic non-destructive technique," J. Power Sources, Vol. 137, No. 1, pp. 128-133, Oct. 2004.

[13] X. Huang, X. Wang, T. Nergaard, J.-S. Lai, X. Xu, and L. Zhu, "Parasitic ringing and design issues of digitally controlled high power interleaved boost converters," IEEE Trans. Power Electron., Vol. 19, No. 5, pp. 1341-1352, Sep. 2004.

[14] R. W. Erickson and D. Maksimovic, Fundamentals of Power Electronics, 2nd ed., Kluwer Academic, 2001.

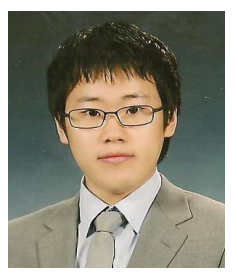

Tae-Hoon Kim was born in Seoul, Republic of Korea, in 1983. He received his B.S. and M.S. in Electrical Engineering from Soongsil University, Republic of Korea, in 2009 and 2011, respectively. His current research interests include switching power converters, power electronic systems, BMS, battery systems, and EV/PHEV charging systems. He is currently a Researcher at the Electronic System R\&D Center of the Korea Automotive Technology Institute.

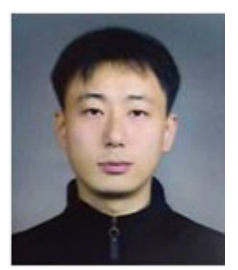

Seung-Jun Lee was born in Seoul, Republic of Korea, in 1974. He received his B.S. and M.S. in Electrical Engineering from Soongsil University, Republic of Korea, in 2006 and 2011, respectively. His current research interests include switching power converters, power electronic systems and battery charge systems for electric forklifts. He is currently a Researcher at the BM TECH Inc.

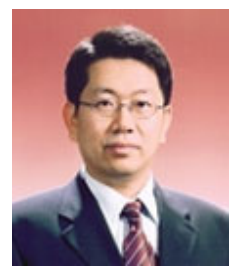

Woojin Choi was born in Seoul, Republic of Korea, in 1967. He received his B.S. and M.S. in Electrical Engineering from Soongsil University, Republic of Korea, in 1990 and 1995, respectively. He received his Ph.D. in Electrical Engineering from Texas A\&M University, USA, in 2004. From 1995 to 1998, he was with Daewoo Heavy Industries as a Research Engineer. His current research interests include the modeling and control of electrochemical energy sources such as fuel cells, batteries and supercapacitors, power conditioning technologies in renewable energy systems, and dc-dc converters for fuel cells and hybrid electric vehicles. 